\title{
Tau Phosphorylation in Myotilinopathies and Desminopathies
}

\author{
Anna Janué, Montse Olive and Isidre Ferrer* \\ Institut de Neuropatologia, Servei Anatomia Patològica, IDIBELL-Hospital Universitari de Bellvitge, Universitat de \\ Barcelona, 08907 Hospitalet de Llobregat, CIBERNED, Spain
}

\begin{abstract}
Tau expression and tau phosphorylation were examined in muscle biopsies of sporadic inclusion body myositis (sIBM), myotilinopathies and desminopathies compared with controls. A panel of anti-tau antibodies including 3Rtau, 4Rtau, phospho-specific tau Thr181, Ser262, Ser396, Ser422 and antibody AT8 (recognizing phosphorylation sites Ser202 and Thr205) and Alzh50 (conformation-dependent) showed diffuse staining in scattered fibers and peripheral or central aggregates in sIBM, myotilinopathies and desminopathies when compared with controls. This was accompanied by significantly increased tau expresion on western blots immunostained with PHF1 antibody, which recognizes a band of $120 \mathrm{kDa}$ corresponding to big tau and several bands of lower molecular weight between 60 and $70 \mathrm{kDa}$, in sIBM and some myotilinopatyhy cases. Increased tau accumulation is not accompanied by increased tau mRNA expression levels but by increased focal immunoreactivity in damaged fibers which is variable from one case to another. Increased tau immunoreactivity is associated with increased focal expression of several kinases known to be involved in tau

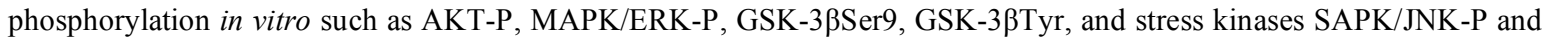
p38-P. These findings confirm previous observations in sIBM, but also demonstrate tau hyper-phosphorylation and abnormal deposition in damaged muscular fibers in myotilinopathies and desminopathies. Furthermore, the present findings suggest the involvement of varied kinases in the process of tau hyper-phosphorylation. GSK-3 $\alpha \beta$ appears to be a cardinal kinase. In addition, activation of stress kinases SAPK/JNK and p38 link previously described oxidative stress with tau phosphorylation in sIBM and myofibrillar myopathies. On the basis of these data, sIBM, myotilinopathies and desminopathies can be considered secondary tauopathies affecting the skeletal muscle.
\end{abstract}

Keywords: Sporadic inclusion body myositis, myotilinopathy, desminopathy, myofribillar myopathy, protein aggregate myopathy, tau kinases.

\section{INTRODUCTION}

Protein aggregate myopathy (PAM) is a term that serves to define myopathies with abnormal protein aggregates [1]. Sporadic inclusion body myositis (sIBM) is a common sporadic inflammatory muscle disease in people older than 50 years which is pathologically characterized by the accumulation of aberrant protein aggregates, rimmed vacuoles, groups of atrophic fibres and focal lymphocyte infiltrates [2-5]. Myofibrillar myopathies (MFM) are a clinically, pathologically and genetically heterogeneous group of muscle disorders defined by focal dissolution of myofibrils, accumulation of the products of myofibrillar degradation and ectopic expression of multiple proteins forming intracellular protein aggregates [1, 6-10]. MFM are caused by mutations in different genes, most of which encode proteins of the sarcomeric Z-disc, including desmin [11-14], $\alpha B$-crystallin [15], myotilin [16, 17], ZASP [18], and filamin $C$ [19]. In addition to the corresponding mutated protein, protein aggregates in MFM are composed of several additional proteins of the Z-disc and cytoskeleton, and dystrophin, chaperones, phospho-tau and $\beta$-amyloid, plectin, gelsolin, cyclin-dependent kinases, clusterin, proteosomal subunits, ubiquitin, mutant ubiquitin and p62 [6, 7, 9, 20-23].

\footnotetext{
*Address correspondence to this author at the Institut de Neuropatologia, Servei Anatomia Patològica, IDIBELL-Hospital Universitari de Bellvitge, Universitat de Barcelona, 08907 Hospitalet de Llobregat, CIBERNED, Spain; Tel: +34 677821456; E-mail: 8082ifa@gmail.com
}

Microtubule-associated protein tau (MAPT) or tau protein is a component of neurons, but it is also found in other nonneuronal tissues including the skeletal muscle [24]. Accumulation of tau protein in muscle disorders was first reported in vacuoles and inclusions in sIBM [25]. Tau is also accumulated in regenerating fibres in oculopharyngeal and Becker muscular dystrophy, dermatomyositis, central core disease, and neurogenic atrophy, as well as in the recovery phase of an attack of malignant hyperthermia [26]. The phosphorylation state of tau has been suggested as the main difference between regenerating fibres and fibres with aberrant tau accumulation [27]. Yet phosphorylated tau in sIBM is found in atrophic non-vacuolated fibres, non-necrotic fibres in the vicinity of inflammatory cells, and fibres with rimmed vacuoles [28]. Finally, tau also appears accumulated in autophagic vacuoles in rat models of vacuolar myopathy induced by chloroquine [29]. Several kinases such as cyclin-dependent kinase 5 (cdk5), extracellular signal-regulated kinase (MAPK/ERK) and glycogen synthase kinase $3 \beta$ (GSK3 $\beta$ ) have been described as being involved in tau phophorylation in SIBM [30-34]. Yet little is known about the characteristics of tau phosphorylation in MFMs. Possible involvement of these kinases, as well as of stress-activated protein kinase/Jun kinase (SAPK/JNK), p38, and protein kinase B (AKT), has not been explored in MFMs.

The present study examines tau phosphorylation in myotilinopathies and desminopathies, in comparison with sIBM to analyze commonalities and differences of tau phosphorylation in these different types of PAM. The 
present observations clearly demonstrate that sIBM and MFM accumulate hyper-phosphorylated big tau a feature that is accompanied by activation and accumulation of several tau kinases in altered muscle fibers. Together, the present observations demonstrate that SIBM, myotilinopathies and desminopathies can be considered secondary tauopathies affecting the skeletal muscle.

\section{MATERIALS AND METHODS}

\section{Patients and Muscle Biopsies}

Muscular biopsy samples from seven controls, five sIBM, five desminopathies and six myotilinopathies were used in the present study. A summary of cases is shown in Table 1.

\section{Table 1. Summary of the Cases}

\begin{tabular}{|c|c|c|c|}
\hline & Age & Mutation & RIN \\
\hline \multicolumn{4}{|c|}{ Controls } \\
\hline 1 & 70 & - & - \\
\hline 2 & 64 & - & 9.7 \\
\hline 3 & 68 & - & 9.5 \\
\hline 4 & 29 & - & 9.3 \\
\hline 5 & 52 & - & 9.5 \\
\hline 6 & 36 & - & 9.1 \\
\hline 7 & 77 & - & 8.8 \\
\hline \multicolumn{4}{|c|}{ sIBM } \\
\hline 8 & 61 & - & 7 \\
\hline 9 & 79 & - & - \\
\hline 10 & 62 & - & 6.9 \\
\hline 11 & 66 & - & 6.9 \\
\hline 12 & 58 & - & 7.7 \\
\hline \multicolumn{4}{|c|}{ Desminopathies } \\
\hline 13 & 41 & DES Pro419Ser & 9.2 \\
\hline 14 & 27 & DES Arg406Trp & 9.3 \\
\hline 15 & 55 & DES Leu392Pro & 9.4 \\
\hline 16 & 28 & DES Ile367Phe & - \\
\hline 17 & 22 & DES Arg406Trp & 7.2 \\
\hline \multicolumn{4}{|c|}{ Myotilinopathies } \\
\hline 18 & 53 & MYOT Ser55Phe & - \\
\hline 19 & 52 & MYOT Ser60Cys & 9.2 \\
\hline 20 & 49 & MYOT Ser55Phe & 9.1 \\
\hline 21 & 78 & MYOT Ser60Phe & 9.5 \\
\hline 22 & 81 & MYOT Lys36Glu & 9.6 \\
\hline 23 & 69 & MYOT Ser60Cys & 9.6 \\
\hline
\end{tabular}

RIN: RNA quality number. DES: demin gene; MYOT: myotilin gene.

\section{Immunohistochemistry}

Cryostat sections, $8 \mu$ m-thick, were fixed with acetone at $-20^{\circ} \mathrm{C}$ for $10 \mathrm{~min}$, incubated with $1 \%$ hydrogen peroxide for
5 min followed by $3 \%$ horse normal serum for $2 \mathrm{~h}$, and then incubated overnight with one of the primary antibodies listed in Table 2. After washing, the sections were processed with LSAB+ System-HRP (Dako, Barcelona, Spain) following the instructions of the manufacturer. The immunoreaction was visualized as a dark blue precipitate using $\mathrm{NH}_{4} \mathrm{NiSO}_{4}$ $(0,05 \mathrm{M})$ diluted in phosphate buffer $(0.1 \mathrm{M})$ with $0.03 \%$ diaminobenzidine (DAB), $\quad 0.04 \% \quad \mathrm{NH}_{4} \mathrm{Cl}$ and $0.001 \%$ hydrogen peroxide. Sections processed only with the secondary antibody were used as negative controls.

\section{Western Blotting}

$50 \mathrm{mg}$ of frozen muscle samples were homogenized with a manual glass homogenizer in ice with $1 \mathrm{ml}$ of homogenizer buffer $(75 \mathrm{mM}$ Tris- $\mathrm{HCl} \mathrm{pH} 6.8,0.001 \%(\mathrm{w} / \mathrm{v})$ bromophenol blue, $15 \%(\mathrm{w} / \mathrm{v})$ SDS, 20\% (v/v) glycerol, 5\% (v/v) $\beta-$ mercaptoethanol) and a mixture of protease inhibitors containing $1 \mathrm{mM}$ phenylmethylsulfonylfluoride (PMSF), 1 $\mu \mathrm{g} / \mathrm{ml}$ pepstatin $\mathrm{A}, 10 \mu \mathrm{g} / \mathrm{ml}$ leupeptin, $10 \mu \mathrm{g} / \mathrm{ml}$ aprotinin. Total homogenates were boiled at $94^{\circ} \mathrm{C}$ for $4 \mathrm{~min}$ and centrifuged at 9,500xg for $5 \mathrm{~min}$. Pellets were discarded, protein concentration of the resulting supernatant was determined by RC DC protein Assay (Bio-Rad, Madrid, Spain) and aliquots were stored at $-80^{\circ} \mathrm{C}$. For western blot studies, $30 \mu \mathrm{g}$ of each sample was processed for sodium dodecyl sulfate polyacrylamide gel electrophoresis (SDSPAGE) $(20 \mathrm{~mA} / \mathrm{gel})$ and then transferred to nitrocellulose membranes $\left(100 \mathrm{~mA} / \mathrm{gel}\right.$ overnight at $\left.4^{\circ} \mathrm{C}\right)$ in a Trans-Blot Cell Transfer System (Bio-rad). Membranes were stained with Ponceau Solution (Sigma, Madrid, Spain) as a transfer quality control, and were immediately blocked with 5\% skimmed milk TBS-T (100 mM Tris base, $1.4 \mathrm{M} \mathrm{NaCl}$ and $0.1 \%(\mathrm{v} / \mathrm{v})$ Tween 20, $\mathrm{pH} 7.4)$ for $1 \mathrm{~h}$ at room temperature. Then the membranes were incubated with one of the primary antibodies, as shown in Table 2, overnight at $4^{\circ} \mathrm{C}$. Subsequently, the membranes were washed with TBS-T and then incubated with the corresponding secondary antibody labeled with horseradish peroxidase (Dako) at a dilution of $1: 1,000$ in the same buffer (TBS-T with 5\% skimmed milk) for $45 \mathrm{~min}$ at room temperature. After washing the membranes with TBS-T, protein bands were detected by the chemiluminescence ECL method (Amersham Biosciences, Little Chalfont, UK). The myosin band of $205 \mathrm{kDa}$ stained with Coomassie Brilliant Blue R (Sigma) in the post-transfer gel was used as a control of protein loading. The densitometric quantification of western blot bands was carried out with TotalLab TL100 v2006 software, and the data obtained were analyzed using Statgraphics Plus v5.1 software. Differences between control and pathologic samples were considered significant when the $p$ value in a tStudent test was lower than $0.05(*)$. All cases in Table 1 were processed in triplicate; representative western blots currently included four controls and four diseased cases.

\section{Cell Culture}

C2C12 myoblasts from C3H mouse strain (CRL 1772, ATCC, Rockville, USA) were grown in Dulbecco's modified Eagle's medium (Gibco ${ }^{\circledR}$ Invitrogen, Barcelona, Spain) containing $15 \%$ fetal bovine serum (Gibco ${ }^{\circledR}$ Invitrogen) and $1 \mathrm{X}$ GIBCO Penicillin- Streptomycin liquid (Gibco ${ }^{8}$ Invitrogen) at $37^{\circ} \mathrm{C}$ in a humidified atmosphere containing $5 \% \mathrm{CO}_{2}$. To make cell lysates, cells were 
Table 2. Antibodies Used in the Present Study

\begin{tabular}{|c|c|c|c|c|c|c|}
\hline Antibody & Type & Species & Manufacturer & WB & IHQ & City, Country \\
\hline Phospho-tau Thr181 & $\mathrm{P}$ & rabbit & Calbiochem & - & $1: 250$ & San Diego, USA \\
\hline Phospho-tau Ser396 & $\mathrm{P}$ & rabbit & Biosource & - & $1: 100$ & Nivelles, Belgium \\
\hline Phospho-tau Ser 422 & $\mathrm{P}$ & rabbit & Calbiochem & - & $1: 50$ & San Diego, USA \\
\hline PHF1 & M & mouse & Davies P & $1: 500$ & - & Albert Einstein College, NY, USA \\
\hline Alz50 & M & mouse & Davies $\mathrm{P}$ & - & $1: 100$ & Albert Einstein College, NY, USA \\
\hline 3Rtau & M & mouse & $\begin{array}{l}\text { Upstate, Millipore } \\
\text { Corporation }\end{array}$ & - & $1: 200$ & Billerica, USA \\
\hline 4 Rtau & M & mouse & $\begin{array}{l}\text { Upstate, Millipore } \\
\text { Corporation }\end{array}$ & - & $1: 25$ & Billerica, USA \\
\hline AT8 & M & mouse & Pierce & - & $1: 50$ & Rockford, USA \\
\hline $\begin{array}{c}\text { Phospho-MAPK 1/2Thr } \\
\text { 202/Tyr } 204 \text { (MAPK/ERK-P) }\end{array}$ & M & mouse & Calbiochem & $1: 100$ & $1: 10$ & San Diego, USA \\
\hline $\begin{array}{c}\text { Phospho-SAPK/JNK } \\
\text { Thr183/Tyr185 (SAPK/JNK- } \\
\text { P) }\end{array}$ & $\mathrm{P}$ & rabbit & Cell Signaling & $1: 100$ & $1: 10$ & Danvers, USA \\
\hline $\begin{array}{l}\text { Phospho-p38 Thr180/Tyr182 } \\
\text { (p38-P) }\end{array}$ & $\mathrm{P}$ & rabbit & Cell Signaling & $1: 250$ & $1: 25$ & Danvers, USA \\
\hline Phospho Akt Thr308 (Akt-P) & $\mathrm{P}$ & rabbit & Cell Signaling & $1: 100$ & $1: 25$ & Danvers, USA \\
\hline GSK $-3 \alpha / \beta$ & M & mouse & Stressgen & $1: 500$ & $1: 50$ & Ann Arbor, USA \\
\hline $\begin{array}{c}\text { Phospho-GSK-3 } \beta \text { Ser9 (GSK- } \\
\text { 3ßSer9) }\end{array}$ & $\mathrm{P}$ & rabbit & Calbiochem & $1: 250$ & $1: 200$ & San Diego, USA \\
\hline 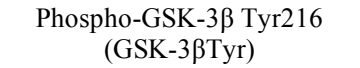 & $\mathrm{P}$ & rabbit & Santa Cruz & - & $1: 250$ & Heidelberg, Germany \\
\hline
\end{tabular}

WB: dilutions used in western blots; IHQ: dilutions used in immunohistochemistry. P: polyclonal; M: monoclonal.

scrapped and resuspended in the same homogenizer buffer used for tissue.

\section{mRNA Isolation and cDNA Synthesis}

Total RNA was purified from frozen muscle biopsies using the RNeasy Fibrous Tissue Mini kit (Qiagen, Madrid, Spain) following the instructions of the supplier. RNA integrity was assessed using an Agilent Bioanalyzer 2100 (Agilent, Las Rozas, Spain). Then, total RNA of each sample was reverse-transcribed to a single stranded cDNA using a High-Capacity cDNA Reverse Transcription Kit (Applied Biosystems, Madrid, Spain). Parallel reactions lacking MultiScribe Reverse Transcriptase were run as negative controls. Cases analyzed are those shown in Table $\mathbf{1}$ with RIN values.

\section{TaqMan Probes and Endogenous Control}

TaqMan Gene Expression Assays (Applied Biosystems) to detect MAPT mRNA were performed by using interrogated sequences NMVं016834.3 (exon boundary 910), NMVं016835.3 (exon boundary 13-14), NMV̈016841.3 (exon boundary 8-9), NMVं001123066.2 (exon boundary 1415), NMV001123067.2 (exon boundary 10-11), and NMV005910.4 (exon boundary 11-12). The human $\beta$ glucuronidase (GUS; 4333767) TaqMan endogenous control was used to normalize MAPT expression levels.

\section{TaqMan Real-Time Polymerase Chain Reaction}

TaqMan polymerase chain reaction (PCR) assays were performed in duplicate on cDNA samples in a MicroAmp Optical 384-Well Reaction Plate sealed with MicroAmp Optical Adhesive Film (Applied Biosystems). Each $20 \mu 1$ PCR reaction was prepared with $9 \mu \mathrm{l}$ of cDNA (diluted $1 / 5$ in all cases) mixed with $1 \mu \mathrm{l}$ of $20 \mathrm{X}$ TaqMan Gene Expression Assay Mix and $10 \mu \mathrm{l}$ of $2 \mathrm{X}$ TaqMan Universal PCR Master Mix (Applied Biosystems), as indicated by the manufacturer. Parallel reactions of all samples were performed in duplicate using GUS endogenous control assay for data normalization. Standard curves for each probe used in the study were obtained with serial dilutions of a muscle control sample. The thermal cycler parameters were set up for $2 \mathrm{~min}$ at $50^{\circ} \mathrm{C}$ (UNG activation), then $10 \mathrm{~min}$ at $95^{\circ} \mathrm{C}$ (enzyme activation), followed by 40 cycles at $95^{\circ} \mathrm{C}$ for 15 sec (denaturation) and $1 \mathrm{~min}$ at $60^{\circ} \mathrm{C}$ (annealing/extension). The fluorescent PCR product was measured with an ABI PRISM 7900HT Fast Sequence Detection System (Applied Biosystems), and the emerging data were captured with the Sequence Detector Software (SDS, 1.9; Applied Biosystems).

\section{Data Processing and Statistical Analysis}

$\mathrm{Ct}$ values for each sample were measured, and their equivalent amount of RNA was interpolated from the standard curves. These values were normalized, and acquired 
data were analyzed using Statgraphics Plus v5.1 software. Differences among control and pathologic samples were analyzed with ANOVA, followed by LSD post-hoc test.

\section{RESULTS}

\section{Immunohistochemistry}

Control Muscle: No tau accumulation, as revealed by 3R, 4R, conformational (Alz50), and phospho-specific antitau antibodies was observed in control cases. Similarly, immunoreactivity to selected tau kinases including MAPK/ERK-P, SAPK/JNK-P, p38-P, GSK-3ßTyr and GSK$3 \beta$ Ser9 was very low and difuse in normal muscle fibres (Fig. 1).

IBM: Increased tau immunoreactivity was observed in scattered muscle fibres, as previously reported [25, 35]. Increased immunoreactivity was demonstrated by using different anti-tau antibodies including those produced against phosphorylated tau, and recognizing with different anti-tau antibodies including thoise directed to $3 \mathrm{Rtau}$ and $4 \mathrm{R}$ tau isoforms, Alz50, AT8 and phospho-specific anti-tauThr181, Ser396 and Ser422 (Fig. 2). Phospho-tau was found in in atrophic fibers, in about $60 \%$ of fibers with rimmed vacuoles, and in non-vacuolated fibers with cytoplasmic protein aggregates in the same way as previously reported $[35,36]$.

Increased immunoreactivity for active kinases SAPK/JNK-P, MAPK/ERK-P, p38-P and AKT-P, and active

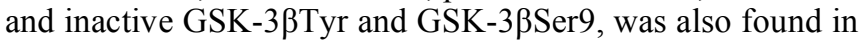
the same fibers that accumulate tau (Fig. 2).

Myotilinopathies: Increased tau immunoreactivity was diffusely present in groups of small fibers, as well as in scattered muscle fibres with abnormal aggregates either located at the periphery or forming central and irregular clumps. Tau deposits were stained with antibodies against 3Rtau and 4Rtau, as well as with the phosphospecific antitau antibodies P-tau Thr181, Ser396, Ser 422, and with the monoclonal antibody AT8, and the conformation-dependent Alz50 (Fig. 3).

Increased immunoreactivity to active kinases AKT-P, MAPK/ERK-P, SAPK/JNK-P and p38-P, as well as GSK$3 \beta$ Tyr and GSK-3ßSer9, was also observed in abnormal muscle fibers containing abnormal protein aggregates (Fig. 4).

Desminopathies: The acumulation of tau was very variable from one case to another. In some cases,

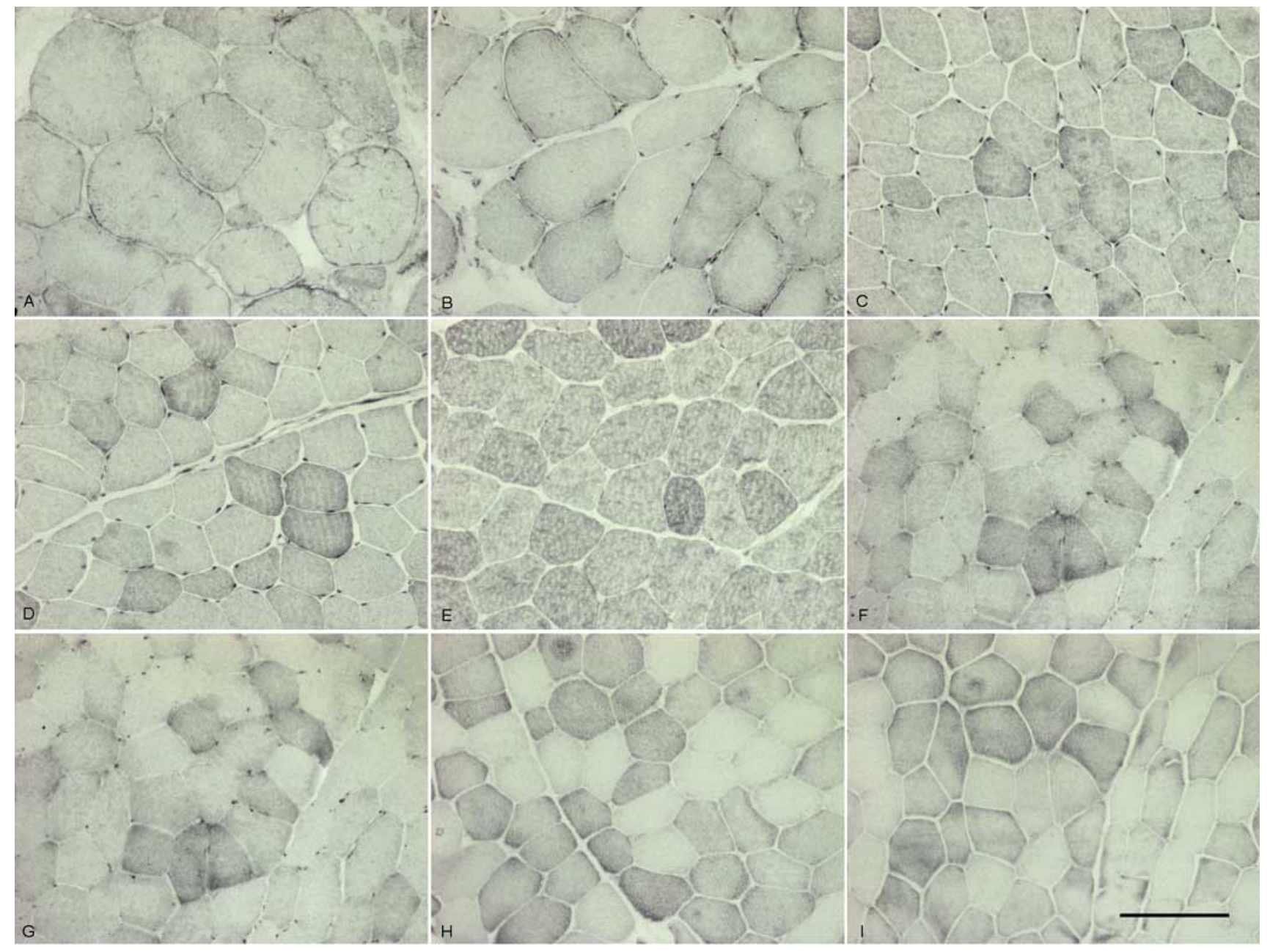

Fig. (1). Control muscle. Immunohistochemistry to: A: 4Rtau; B: 3Rtau; C: P-tau Thr 181; D: P-tau Ser422; E: P-tau-396; F: AKT-P; G: MAPK/ERK-P; H: p38-P; I: SAPK/JNK-P. Cryostat sections without counterstaining. Bar $=50 \mu \mathrm{m}$. 


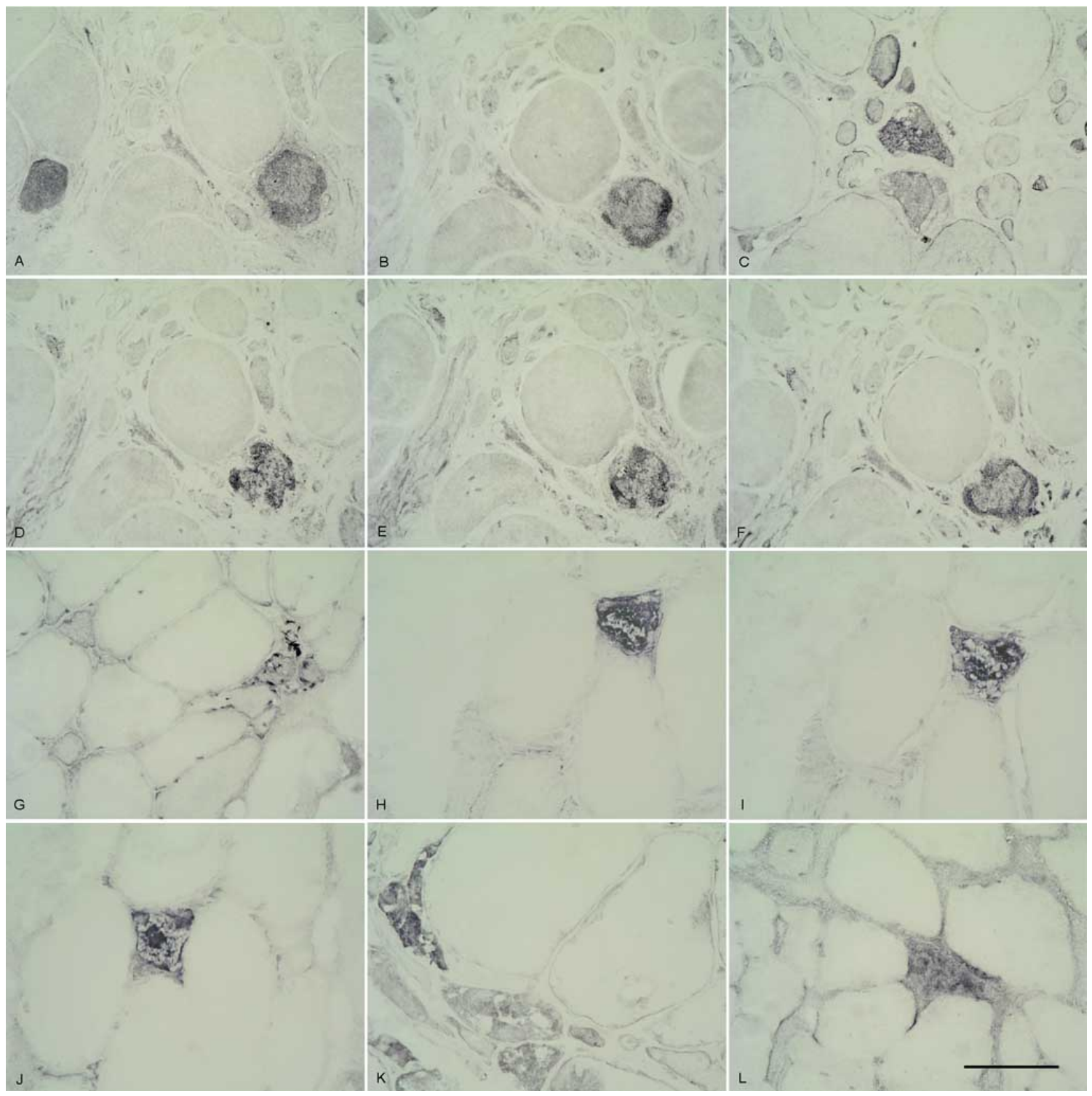

Fig. (2). sIBMA. Positive fibers immunoreactive for A: 4Rtau; B: 3Rtau; C: P-tau Thr 181; D: Alz50; E: AT8; F: P-tau Ser422; G: AKT-P;

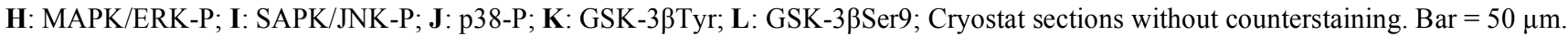

accumulation of 3Rtau, 4Rtau and phospho-tau was very discrete and restricted to very small diffuse amounts in scattered fibres in most cases. Yet increased tau immunoreactivity was present in other cases. The characteristics of these deposits resembled those described in sIBM and myotilinopathy (Fig. 5). Paralleling tau accumulation, increased immunoreactivity for tau kinases was found in scattered fibres in desminopathy (Fig. 5).

\section{Western Blotting}

Antibodies to PHF1 showed a band of about $120 \mathrm{kDa}$ in control and diseased cases. A band of slightly lower molecular weight was detected in $\mathrm{C} 2 \mathrm{C} 12$ cells run in parallel. In addition to the big tau, several bands of lower molecular weight, some of them between 60 and $70 \mathrm{kDa}$, and others of about $40 \mathrm{kDa}$, were detected after long exposure (Fig. 6).
Densitometric studies revealed significantly increased levels of the big tau in sIBM when compared with controls (Student t-test, $\mathrm{p}<0.05$ ). Increased expression levels were seen in two cases with myotilinopathy but not in the other two when compared with controls. Differences were not significant between controls and myotilinopathies as a group (Fig. 6). Expression levels of PHF1 in desminopathies were variable from one case to another; but total expression levels were not significantly different from those found in controls (Fig. 6).

Antibodies to GSK $-3 \alpha / \beta$ showed two bands of $51 \mathrm{kDa}$ and $47 \mathrm{kDa}$ corresponding to $\alpha$ and $\beta$, respectively, in control and diseased samples. Increased expression of GSK$3 \alpha / \beta$ was found in sIBM, myotilinopathy and desminopathy cases when compared with controls. Densitometric studies of all cases revealed significant differences (Student t-test, 


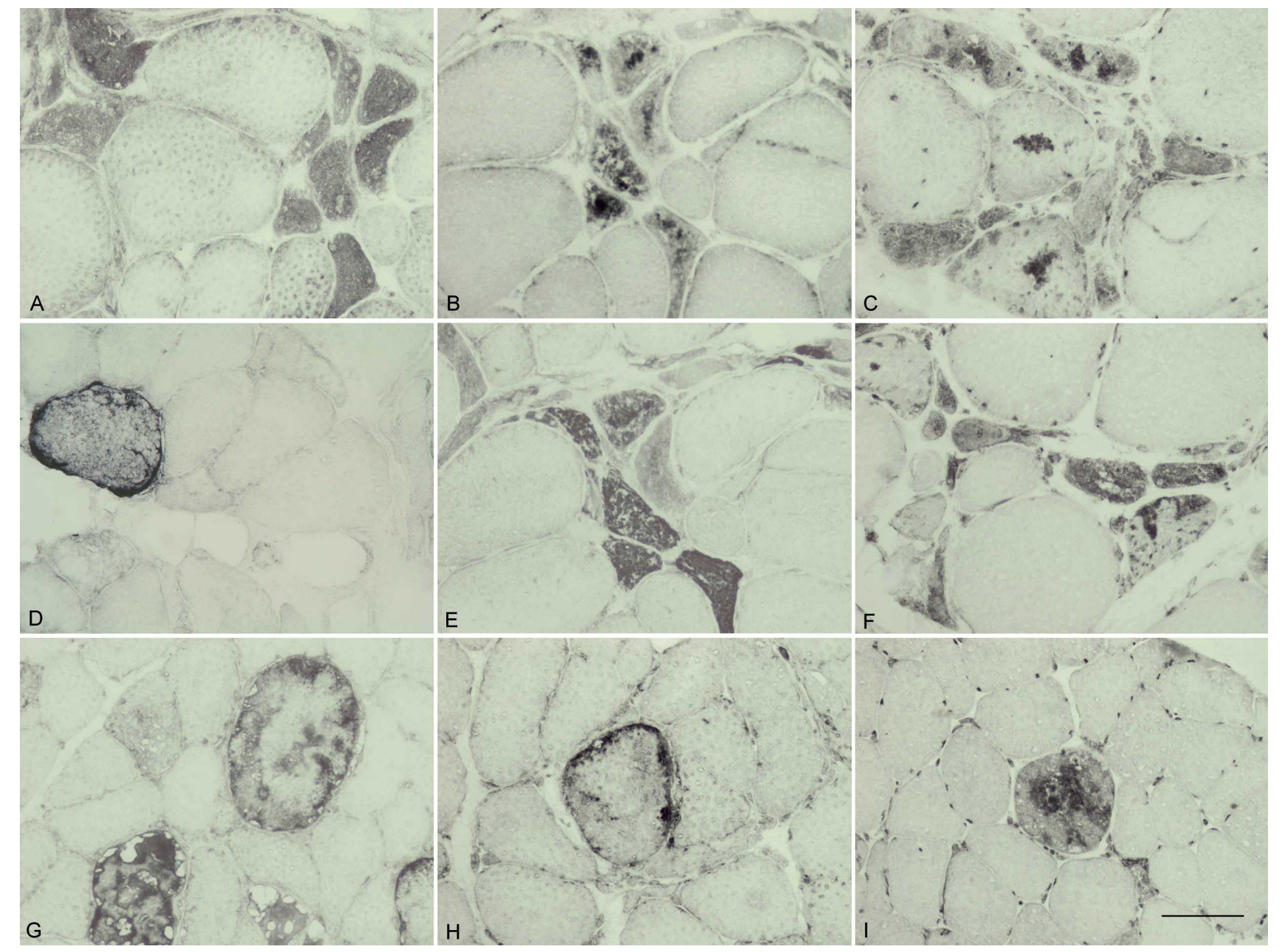

Fig. (3). Myotilinopathy. Positive fibers immunoreactive for A: 3Rtau; B: 4Rtau; C: P-tau Thr181; D: Alz50; E: P-tau Ser422; F: AT8; G: 3Rtau; H: P-tau Ser396; I: P-tau-Thr181. A-F, correspond to one case; G-I: correspond to another case. Cryostat sections without counterstaining. Bar $=50 \mu \mathrm{m}$.
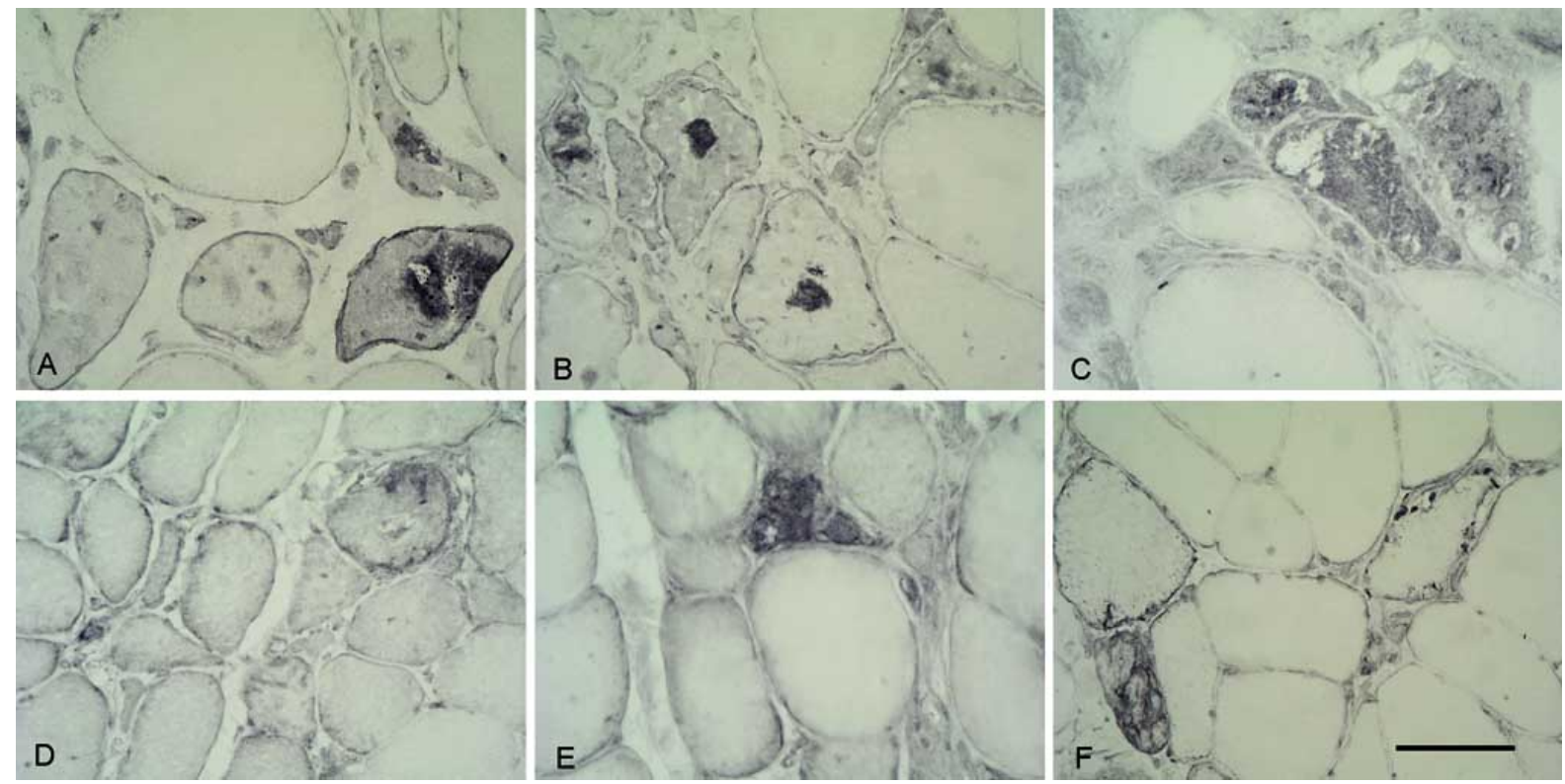

Fig. (4). Myotilinopathy. Positive fibers immunoreactive for A: AKT-P; B: MAPK/ERK-P; C: SAPK/JNK-P; D: p38-P; E: GSK-3ßTyr; F: GSK-3ßSer9. Cryostat sections without counterstaining. Bar $=50 \mu \mathrm{m}$. 


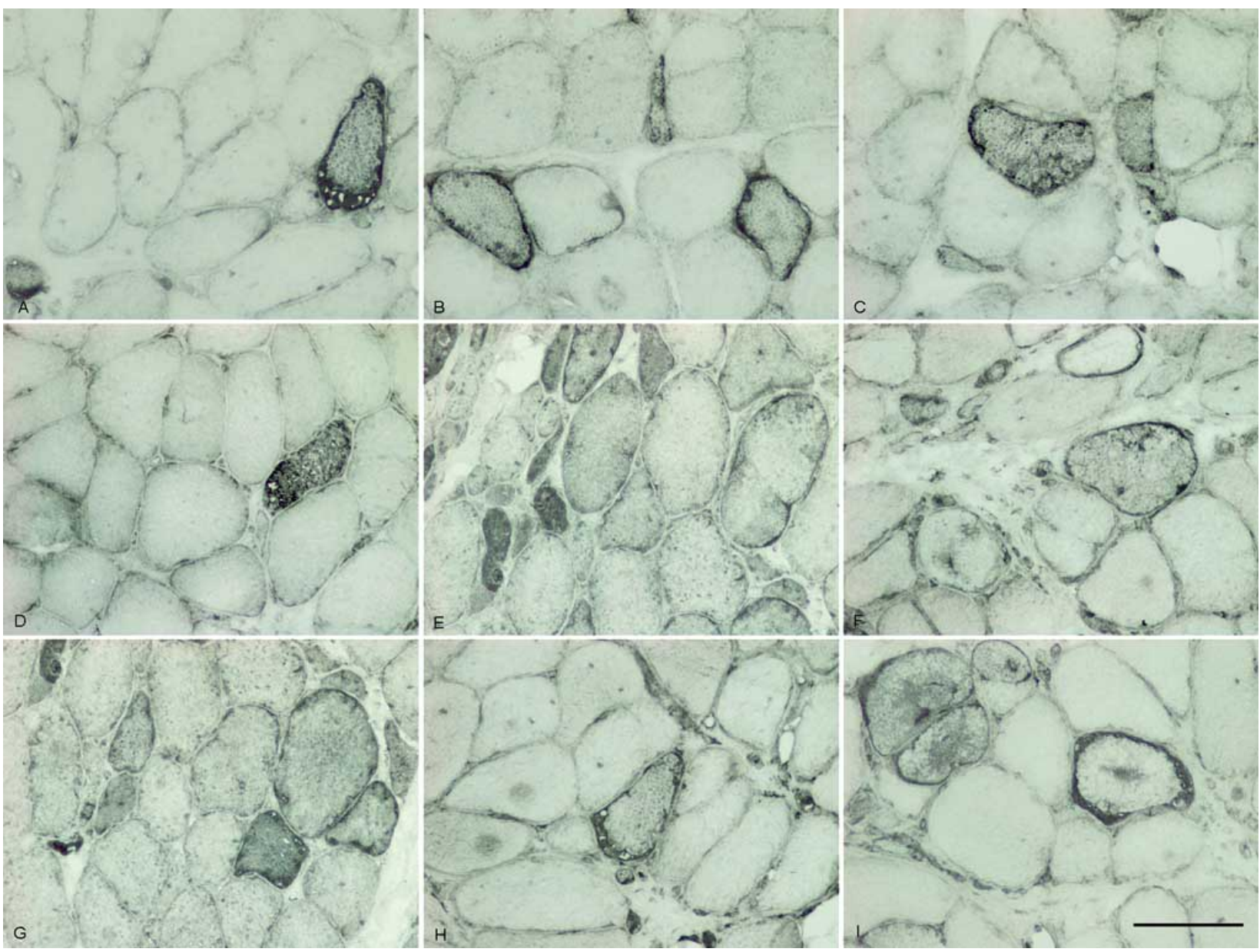

Fig. (5). Desminopathy. Positive fibers immunoreactive fo A: 3Rtau; B: 4Rtau; C: Alz50; D: P-tau Thr181; E: P-tau Ser 422; F: P-tau-Ser 396; G: SAPK/JNK-P; H: p38-P; I: GSK-3ßSer9. Cryostat sections without counterstaining. Bar $=50 \mu \mathrm{m}$.

\section{PHF1 antibody}
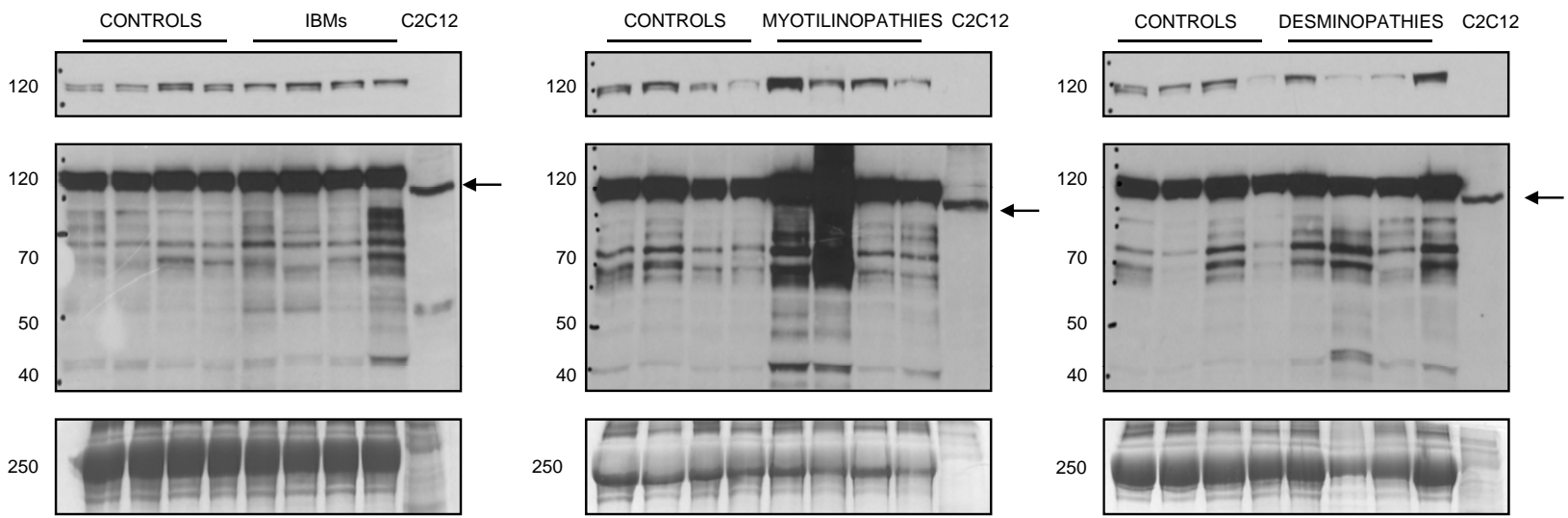

Fig. (6). Representative gel electrophoresis and western blotting of total homogenates of controls, sIBM, myotilinopathy and desminopathy cases run in parallel with $\mathrm{C} 2 \mathrm{C} 12$ cells of muscular origin using the PHF1 antibody. Two exposure times are shown in every case. A band of about $120 \mathrm{kDa}$ is observed in control and diseased cases. A band of slightly lower molecular weight is also present in C2C12 cells (arrow) after longer exposure of the membranes. In addition, other bands of molecular weight between 60 and $70 \mathrm{kDa}$ are observed in all muscle samples. Therefore, this pattern appears not to be disease-dependent. However, increased immunoreactivity of the bands is found in certrain sIBM cases, and especially in two cases with myotilinopathy. The myosin band of $205 \mathrm{kDa}$ stained with Coomassie Brilliant Blue R in the post-transfer gel was used as a control of protein loading. Densitometric studies of all cases ( 7 controls, 5 sIBM, 5 desminopathies and 6 myotilinopathies) revealed significantly increased levels of the big tau in sIBM when compared with controls (Student t-test, $\mathrm{p}<0.05)$ but not in myotilinopathies (considered as a group) due to individual variations. 


\section{GSK-3 $\alpha / \beta$}
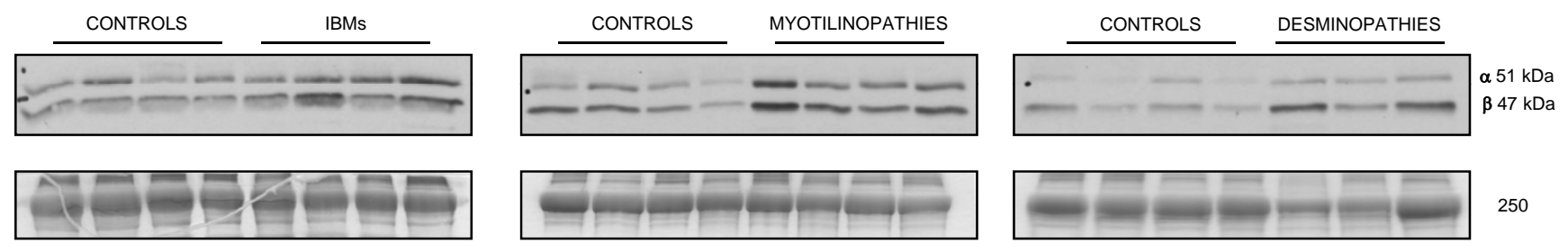

Fig. (7). Representative gel electrophoresis and western blotting of total homogenates of controls, sIBM, myotilinopathy and desminopathy cases using the GSK-3 $\alpha / \beta$ antibody. Increased expression is found in sIBM, myotilinopathy and desminopathy cases when compared with controls. Comparison between pathologic cases and corresponding controls was carried out in samples run in parallel. The myosin band of $205 \mathrm{kDa}$ stained with Coomassie Brilliant Blue R in the post-transfer gel was used as a control of protein loading. Densitometric study of the $\alpha$ band revealed significant differences (Student t-test, $\mathrm{p}<0.05$ ) between control and sIBM and myotilinopathy. Yet no significant differences were seen between control and desminopathy cases.

$\mathrm{p}<0.05)$ of the band corresponding to GSK-3 $\alpha$ but not of GSK-3 $\beta$ between control and sIBM and myotilinopathy. No significant differences were seen between controls and desminopathies.

\section{MAPT mRNA Expression Levels}

MAPT mRNA expression was detected in all cases analysed in this study including controls, sIBM, myotilinopathies and desminopathies. No significant differences were seen between control and diseased cases when MAPT values were normalized with GUS (data not shown).

\section{DISCUSSION}

PHF1 antibody recognizes a protein of about $120 \mathrm{kDa}$ in total homogenates of skeletal muscle biopsies in the present series. The molecular weight of this isoform correlates with that previously described as big tau in the peripheral nervous system [37, 38]. Big tau is generated as a result of alternative splicing from the same gene that encodes other tau isoforms. The protein has the same sequence as the longest known tau isoform in the central nervous system with an additional 254 amino acid insert in the amino terminal half [37]. High molecular tau in skeletal muscle was first described in dermatomyositis and central core disease, and in the recovery phase of an attack of malignant hyperthermia [26]. A doublet of $60-62 \mathrm{kDa}$ was previously reported in sIBM cases [28]. Other bands between 60 and $70 \mathrm{kDa}$, as well as bands of lower molecular weight were also recognized with the PHF1 antibody in the skeletal muscle in the present series of sIBM and myotilinopathy cases. Myoblast cell line $\mathrm{C} 2 \mathrm{C} 12$ was used to demonstrate big tau in immature muscular cells. Curiously, the PHF1 antibody recognized a band of high molecular weight corresponding to some big tau in $\mathrm{C} 2 \mathrm{C} 12$ cells although the molecular weight was slightly lower that big tau in mature human muscle. The reasons of these differences are not known and we wonder whether big tau isoforms may also occur in developing muscle cells, as it occurs in the central nervous system with the low molecular weight fetal tau isoform the expression of which is practically absent in mature nerve cells. It is known that the epitope recognized by the PHF1 antibody corresponds to amino acids 404-441 of human tau and also comprising the phospho-epitope Ser 396/404 [38, 39]. Thus, the phosphorylation of this site appears to be an event involved in the normal function of this tau isoform in skeletal muscle. The detection of the band of $120 \mathrm{kDa}$ and the lower bands between 60 and $70 \mathrm{kDa}$ in control and diseased cases does not support the concept of a pattern specific to a particular pathology. The difference between control and pathological cases is quantitatitive rather than qualitative. The expression of PHF1 is significantly increased in sIBM when compared with controls, and markedly increased in some biopsies of myotilinopathy.

Tau deposition and increased tau phosphorylation in sIBM was reported many years ago [25] and was clearly characterized by using several antibodies in optical and immunoelectronmicroscopical sections [35]. More recent immunohistochemical studies evidenced tau phosphorylation in MFMs as well $[9,21]$. A recent study has suggested that immunostaining of tau in sIBM, as recognized by antibodies tau-5, pS422, and SMI-31, is not specific, as these antibodies stain myonuclei and proteins other than tau [40]. However, the present findings further support tau accumulation and focal deposition of phospho-tau in SIBM and certain MFMs. Myotilinopathies have a similar pattern of tau phosphorylation and tau deposition when compared with sIBM. Deposits of tau isoforms recognized with antibodies against $3 R$ and $4 R$ are found equally in SIBM and myotilinopathy. Furthermore, phospho-specific antibodies against Thr181, Ser396 and Ser422, as well as antibodies AT8 (recognizing phosphorylation sites Ser202 and Thr205) and Alz50 (conformation-dependent) [41], facilitate the immunodetection of aberrant tau accumulation in the form of diffuse deposits in small fibers, peripheral aggregates in muscle fibres, and central deposits. Although not always accompanied by increased total levels on western blots (data not shown), the focal positivity for different antibodies raised against different phosphorylated and nonphosphorylated tau epitopes is a robust confirmation of aberrant tau deposition in sIBM, myotilinopathy and a number of cases with desminopathy. These findings further supporting commonalities and differences between desminopathy and myotilinopathy $[9,17,23,42,43]$.

Several kinases have the capacity to phosphorylate tau in vitro and in vivo. MAPK/ERK and GSK-3 $\beta$, among others, 
have been described as being involved in tau phophorylation in sIBM [30-34]. The present immunohistochemical data support the suggested involvement of AKT, MAPK/ERK and GSK-3 in tau phosphorylation in SIBM and myotilinopathies as well. In addition, phosphorylated stress kinases SAPK/JNK and p38 are also accumulated in fibres with abnormal tau phosphorylation. Whether these kinases activate tau phosphorylation, or are merely sequestered by abnormal protein aggregates in myotilinopathy, can not be resolved on the basis of the present biopsy series. However, the demonstration of oxidative stress and oxidative cell damage in MFMs [9, 44, 45] puts forward a link among oxidative stress, activation of stress kinases and tau phosphorylation.

The consequences of hyper-tau phosphorylation in SIBM and MFM can only be hypothesized on the basis of the few available data. As in other cell types, microtubules in skeletal muscle are probably implicated in muscle differentiation, morphology and contractile activity [46]. This process is modulated by interaction with several proteins including microtubule-associated proteins of high molecular weight, tau and muscle specific proteins such as members of the RING finger (MURF) family, specifically MURF-2 and MURF-3 [47]. Regarding myotilinopathies, cellular models are probably needed to elucidate the interactions of all these components under normal conditions and in muscle cells bearing mutant myotilin.

Finally, the term tauopathy is currently used to name degenerative diseases of the nervous system with abnormal hyper-phosphorylated tau aggregates such as Alzheimer disease, progressive supranuclear palsy, corticobasal degeneration, argyrophilic grain disease, Pick disease and frontotemporal lobe degeneration linked to mutations in MAPT gene, among others, in all of which specific kinases play pivotal roles in tau hyper-phosphorylation [48, 49]. sIBM and MFM can be properly considered secondary tauopathies because of the accumulation of hyperphosphorylated tau in association with abnormal protein aggregates.

\section{ACKNOWLEDGEMENTS}

This work was supported with FIS PI08-0574 grant. We wish to thank P. Davies for the gift of the antibody PHF1 and Alz50, M. Martinez for the preparation of $\mathrm{C} 2 \mathrm{C} 12$ cells, D. Moreno for help in immunohistochemistry, and $\mathrm{T}$. Yohannan for editorial assistance.

\section{REFERENCES}

[1] Goebel HH, Fardeau M, Olivé M, Schröder R. 156th ENMC International Workshop: Desmin and protein aggregate myopathies, 9-11 November 2007, Naarden, The Netherlands. Neuromuscul Disord 2008; 18: 583-92.

[2] Dalakas MC. Sporadic inclusion body myositis-diagnosis, pathogenesis and therapeutic strategies. Neurology 2006; 2: 43747.

[3] Askanas V, Engel WK. Inclusion-body myositis, a multifactorial muscle disease associated with aging: current concepts of pathogenesis. Curr Opin Rheumatol 2007; 19: 550-59.

[4] Needham M, Mastaglia FL. Inclusion body myositis: current pathogenetic concepts and diagnostic and therapeutic approaches. Lancet Neurol 2007; 6: 620-31.

[5] Askanas V, King EWK. Inclusion-body myositis: muscle-fiber molecular pathology and possible pathogenic significance of its similarity to Alzheimer's and Parkinson's disease brains. Acta Neuropathol 2008; 116: 583-95.

[6] Nakano S, Engel AG, Waclawik AJ, Emslie-Smith AM, Busis NA. Myofibrillar myopathy with abnormal foci of desmin positivity. I Light and electron miscroscopy analysis of 10 cases. J Neuropathol Exp Neurol 1996; 55: 549-62.

[7] De Bleecker JL, Engel AG, Ertl B. Myofibrillar myopathy with foci of desmin positivity II. Immunocytochemical analysis reveals accumulation of multiple other proteins. J Neuropathol Exp Neurol 1996; 55: 563-77.

[8] Selcen D, Ohno K, Engel AG. Myofibrillar myopathy: clinical, morphological and genetic studies in 63 patients. Brain 2004; 127: 439-51.

[9] Selcen D. Myofibrillar myopathies. Curr Opin Neurol 2008; 21: 585-89.

[10] Ferrer I, Olive M. Molecular pathology of myofibrillar myopathies. Exp Rev Mol Med 2008; 10: e25.

[11] Goldfarb LG, Park KY, Cervenáková L, et al. Missense mutations in desmin associated with familial cardiac and skeletal myopathy. Nat Genet 1998;19: 402-3.

[12] Muñoz-Mármol AM, Strasser G, Isamat M, et al. A dysfunctional desmin mutation in a patient with severe generalised myopathy. Proc Natl Acad Sci USA 1998; 95: 11312-7.

[13] Goldfarb LG, Vicart P, Goebel HH, Dalakas MC. Desmin myopathy. Brain 2004; 127: 723-34.

[14] Olivé M, Goldfarb LG, Shatunov A, Fischer D, Ferrer I. Myotilinopathy: refining the clinical and myopathological phenotype. Brain 2005; 128: 2315-26.

[15] Vicart P, Caron A, Guicheney P, et al. A missense mutation in the $\alpha \mathrm{B}$-crystallin chaperone gene causes a desmin-related myopathy. Nat Genet 1998; 20: 92-95.

[16] Selcen D, Engel AG. Mutations in myotilin cause myofibrillar myopathy. Neurology 2004; 62: 1363-71.

[17] Olive M, Armstrong J, Miralles F, et al. Phenotypic patterns of desminopathy associated with three novel mutations in the desmin gene. Neuromusc Disor 2007; 17: 443-50.

[18] Selcen D, Engel AG. Mutations in ZASP define a novel form of Muscular Dystrophy in humans. Ann Neurol 2005; 57: 269-76.

[19] Vorgerd M, van de Ven PF, Bruchertseifer V, et al. A mutation in the dimerization domain of filamin causes a novel type of autosomal dominant myofibrillar myopathy. Am J Hum Genet 2005; 77: 297-304

[20] Nakano S, Engel AG, Akiguchi I, Kimura J. Myofibrillar myopathy. III. Abnormal expression of cyclin-dependent kinases and nuclear proteins. J Neuropathol Exp Neurol 1997; 56: 850-56.

[21] Ferrer I, Martín B, Castaño JG, Lucas JJ, Moreno D, Olivé M. Proteasomal expression and activity, and induction of the immunoproteasome in myofibrillar myopathies and inclusion body myositis. J Neuropathol Exp Neurol 2004; 63: 484-88.

[22] Ferrer I, Carmona M, Blanco R, Moreno D, Torrejón-Escribano B, Olivé M. Involvement of clusterin and the aggresome in abnormal protein deposits in myofibrillar myopathies and inclusion body myositis. Brain Pathol 2005; 15: 101-8.

[23] Olivé M, van Leeuwen FW, Janué A, Moreno D, TorrejónEscribano B, Ferrer I. Expression of mutant ubiquitin $\left(\mathrm{UBB}^{+1}\right)$ and p62 in myotilinopathies and desminopathies. Neuropathol Appl Neurobiol 2007; 34: 76-87.

[24] Gu Y, Oyama F, Ihara Y. Tau is widely expressed in rat tissues. J Neurochem 1996; 67: 1235-44.

[25] Askanas V, Engel WK, Bilak M, Alvarez RB, Selkoe DJ. Twisted tubulofilaments of inclusion body myositis muscle resemble paired helical filaments of Alzheimer brain and contain hyperphosphorylated tau. Am J Pathol 1994; 144: 177-87.

[26] Lübke U, Six J, Villanova M, et al. Microtubule-associated protein tau epitopes are present in fiber lesions in diverse muscle disorders. Am J Pathol 1994; 145: 175-88.

[27] Murakami N, Ishiguro K, Ihara Y, Nonaka I, Sugita H, Imahori K. Tau protein immunoreactivity in muscle fibers with rimmed vacuoles differs from that in regenerating muscle fibers. Acta Neuropathol 1995; 90: 467-71.

[28] Maurage CA, Bussière T, Sergeant N, et al. Tau aggregates are abnormally phosphorylated in inclusion body myositis and have an immunoelectrophoretic profile distinct from other tauopathies. Neuropathol Appl Neurobiol 2004; 30: 624-34. 
[29] Murakami N, Oyama F, Gu Y, McLennan IS, Nonaka I, Ihara Y. Accumulation of tau in autophagic vacuoles in chloroquine myopathy. J Neuropathol Exp Neurol 1998; 57: 664-73.

[30] Nakano S, Akiguchi I, Nakamura S, Satoi H, Kawashima S, Kimura J. Aberrant expression of cyclin-dependent kinase 5 in inclusion body myositis. Neurology 1999; 53: 1671-76.

[31] Wilczynski GM, Engel WK, Askanas V. Association of active extracellular signal-regulated protein kinase with paired helical filaments of inclusion-body myositis muscle suggests its role in inclusion-body myositis tau phosphorylation. Am J Pathol 2000; 156: $1835-40$.

[32] Wilczynski GM, Engel WK, Askanas V. Cyclin-dependent kinase 5 colocalizes with phosphorylated tau in human inclusion-body myositis paired-helical filaments and may play a role in tau phosphorylation. Neurosci Lett 2000; 293: 33-6.

[33] Nakano S, Shinde A, Kawashima S, Nakamura S, Akiguchi I, Kimura J. Inclusion body myositis: expression of extracellular signal-regulated kinase and its substrate. Neurology 2001; 56: 8793.

[34] Kitazawa M, Trinh DN, LaFerla FM. Inflammation induces tau pathology in inclusion body myositis model via glycogen synthase kinase-3beta. Ann Neurol 2008; 64: 15-24.

[35] Mirabella M, Alvarez RB, Bilak M, Engel WK, Askanas V. Difference in expression of phosphorylated tau epitopes between sporadic inclusion-body myositis and hereditary inclusion-body myopathies. J Neuropathol Exp Neurol 1996; 55: 774-86.

[36] Otvos L Jr, Feiner L, Lang E, Szendrei GI, Goedert M, Lee VM. Monoclonal antibody PHF-1 recognizes tau protein phosphorylated at serine residues 396 and 404. J Neurosci Res 1994; 39: 669-73.

[37] Goedert MG, Spillantini MG, Crowther RA. Cloning of a big tau microtubule-associated protein characteristic of the peripheral nervous system. Proc Natl Acad Sci USA 1992; 89: 1983-7.

[38] Couchie D, Mavilia C, Georgieff IS, Liemi RKH, Shelanski ML, Nunez J. Primary structure of high molecular weight tau present in the peripheral nervous system. Proc Natl Acad Sci USA 1992; 89: 4378-81.
[39] Maas T, Eidenmüller J, Brandt R. Interaction of tau with the neural membrane cortex is regulated by phosphorylation at sites that are modified in paired helical filaments. J Biol Chem 2000; 275: 15733-740.

[40] Salajegheh M, Pinkus JL, Nazareno R, Amato AA, Parker KC, Greenberg SA. Nature of "Tau" immunoreactivity in normal myonuclei and inclusion body myositis. Muscle Nerve 2009; 40: 520-28.

[41] Carmel G, Mager EM, Binder LI, Kuret J. The structural basis of monoclonal antibody Alz50's selectivity for Alzheimer's disease pathology. J Biol Chem 1996; 271: 32789-95.

[42] Fischer D, Clemen CS, Olive M, et al. Different early patogenesis in myotilinopathy compared to primary desminopathy. Neuromusc Disord 2006; 16: 361-7.

[43] Claeys KG, van der Ven PF, Behin A, et al. Differential involvement of sarcomeric proteins in myofibrillar myopathies: a morphological and immunohistochemical study. Acta Neuropathol 2009; 117: 293-307.

[44] Janue A, Odena MA, Oliveira E, Olive M, Ferrer I. Desmin is oxidized and nitrated in affected muscles in myotilinopathies and desminopathies. J Neuropathol Exp Neurol 2007; 66: 711-23.

[45] Janué A, Olive M, Ferrer I. Oxidative stress in desminopathies and myotilinopathies: A link between oxidative damage and abnormal protein aggregation. Brain Pathol 2007; 17: 377-88

[46] Clark KA, McElhinny AS, Beckerle MC, Gregorio CC. Striated muscle cytoarchitecture: An intricate web of form and function. Annu Rev Cell Dev Biol 2002; 18: 637-706.

[47] McElhinny AS, Perry CN, Witt CC, Labeit S, Gregorio CC. Muscle-specific RING finger-2 (MURF-2) is important for microtubule, intermediate filament and sarcomeric M-line maintenance in striated muscle development. J Cell Sci 2004; 117 $3175-88$.

[48] Hernández F, Avila J. Tauopathies. Cell Mol Life Sci 2007; 64: 2219-33.

[49] Ferrer I. Stress kinases involved in tau phosphorylation in Alzheimer's disease, tauopathies and APP transgenic mice. Neurotox Res 2004; 6: 469-75. 